Hydrol. Earth Syst. Sci., 17, 2501-2514, 2013

www.hydrol-earth-syst-sci.net/17/2501/2013/

doi:10.5194/hess-17-2501-2013

(c) Author(s) 2013. CC Attribution 3.0 License.

\title{
Expected changes in future temperature extremes and their elevation dependency over the Yellow River source region
}

\author{
Y. Hu ${ }^{1,2}$, S. Maskey ${ }^{2}$, and S. Uhlenbrook ${ }^{2,3}$ \\ ${ }^{1}$ Yellow River Conservancy Commission, Zhengzhou, 450003, China \\ ${ }^{2}$ UNESCO-IHE Institute for Water Education, P.O. Box 3015, 2601 DA Delft, the Netherlands \\ ${ }^{3}$ Delft University of Technology, Department of Water Resources, P.O. Box 5048, 2600 GA Delft, the Netherlands
}

Correspondence to: Y. Hu (y.hu@unesco-ihe.org)

Received: 12 November 2012 - Published in Hydrol. Earth Syst. Sci. Discuss.: 10 December 2012

Revised: 23 April 2013 - Accepted: 8 June 2013 - Published: 5 July 2013

\begin{abstract}
Using the Statistical DownScaling Model (SDSM) and the outputs from two global climate models, we investigate possible changes in mean and extreme temperature indices and their elevation dependency over the Yellow River source region for the two future periods 2046-2065 and 2081-2100 under the IPCC SRES A2, A1B and B1 emission scenarios. Changes in interannual variability of mean and extreme temperature indices are also analyzed. The validation results show that SDSM performs better in reproducing the maximum temperature-related indices than the minimum temperature-related indices. The projections show that by the middle and end of the 21st century all parts of the study region may experience increases in both mean and extreme temperature in all seasons, along with an increase in the frequency of hot days and warm nights and with a decrease in frost days. By the end of the 21st century, interannual variability increases in all seasons for the frequency of hot days and warm nights and in spring for frost days while it decreases for frost days in summer. Autumn demonstrates pronounced elevation-dependent changes in which around six out of eight indices show significant increasing changes with elevation.
\end{abstract}

\section{Introduction}

The Yellow River source region is situated in the northeast Tibetan Plateau, which has been identified as a "climate change hot-spot" and one of the most sensitive areas to greenhouse gas (GHG)-induced global warming (Giorgi, 2006). This region is geographically unique, possesses highly variable climate and topography, and plays a critical role for downstream water supply. A growing number of evidences suggest that this region and its surroundings are experiencing warming and accelerated glacier retreat (Liu and Chen, 2000; You et al., 2008; Liu et al., 2009; Qin et al., 2009; Rangwala et al., 2009; Hu et al., 2011, 2012; Immerzeel et al., 2010; Maskey et al., 2011; Shrestha and Aryal, 2011). In line with global climate projection, this warming is expected to continue into the future under enhanced greenhouse gas forcing (IPCC, 2007). A primary concern in estimating impacts from climate changes are the potential changes in variability and hence extreme events that could be associated with global climate change (Marengo et al., 2010). Recent model studies (based on both global and regional climate models) suggest that the 21 st century is very likely to be characterized by more frequent and intense temperature extremes, which are not only due to the mean warming, but also due to changes in temperature variability (IPCC, 2007; Tebaldi et al., 2006; Kjellström et al., 2007; Fischer and Schär, 2009). Regional temperature extremes have recently received increasing attention given the vulnerability of our societies to such events. This is particularly true for mountain regions where the observed or projected warmings are generally greater than at low-elevation regions (Diaz and Bradley, 1997; Beniston et al., 1997; Rangwala et al., 2009; Liu et al., 2009; Qin et al., 2009; Rangwala and Miller, 2012; Viviroli et al., 2011). Moreover, some mountain regions have demonstrated an elevation dependency in surface warming (i.e. greater warming rates at higher altitude) in the latter half of the 20th century and/or during the 21st century (Beniston and Rebetez, 1996; Diaz and Bradley, 


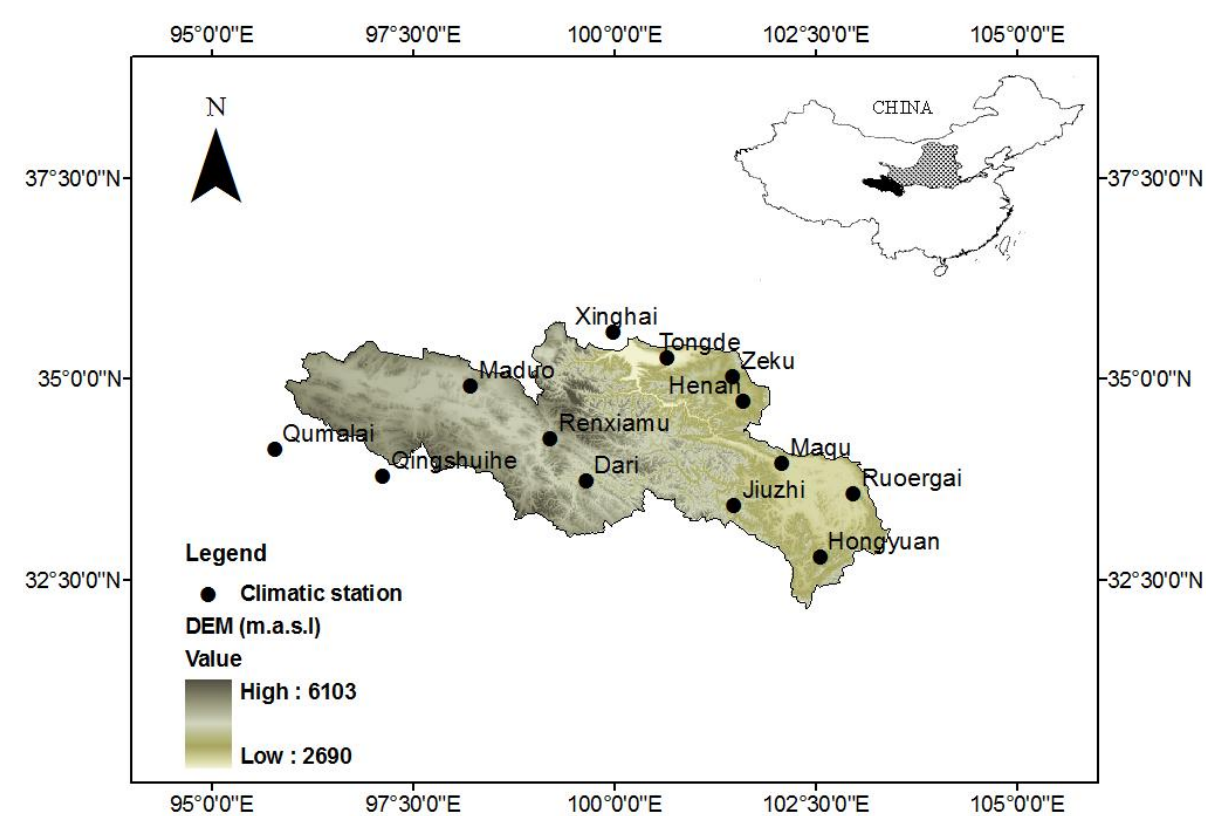

Fig. 1. Map of the study area showing the locations (filled circle) of climatic stations. The smaller map in the upper right corner presents the location the Yellow River source region in China (black shaded area).

1997; Giorgi et al., 1997; Liu and Chen, 2000; Chen et al., 2003; Diaz and Eischeid, 2007; Rangwala et al., 2009, 2010; Liu et al., 2009). Within the Tibetan Plateau, previous studies found indications for enhanced warming at higher elevation (Liu and Chen, 2000; Chen et al., 2003; Liu et al., 2009; Qin et al., 2009; Rangwala et al., 2009, 2010), while others reported no enhanced or even weakening warming at higher elevations (You et al., 2008; Lu et al., 2010). Although a number of climate change studies over the Yellow River source region have been reported in the literature, possible changes in future temperature extremes and their relationship with elevation are yet to be fully explored. Earlier studies Xu et al. (2009) and Wang et al. (2012) reported increases in the mean $\left(T_{\text {mean }}\right)$, maximum $\left(T_{\max }\right)$, and minimum $\left(T_{\min }\right)$ temperature over this region for the 21 st century. This study complements the previous studies by including estimated changes in future temperature extremes using a number of indices and their elevation dependency. Changes in interannual temperature variability are also examined in the present study. Among different downscaling approaches, statistical downscaling is the most widely used one to construct climate change information at a station or local scales because of its relative simplicity and less intensive computation. Moreover, previous studies reported in the literature found statistical downscaling showing similar skill as dynamical downscaling and no indication of either downscaling method having a direct advantage over the other (Haylock et al., 2006; Schoof et al., 2009). In the present study the Statistical DownScaling Model (Wilby et al., 2002) is applied to downscale the outputs of the two driving GCMs under the IPCC SRES A2, A1B and B1 emission scenarios.

\section{Study area and data}

\subsection{Study area}

The study region is located in the northeast Qinghai-Tibetan Plateau, spanning between $95^{\circ} 50^{\prime} 45^{\prime \prime} \mathrm{E}-103^{\circ} 28^{\prime} 11^{\prime \prime} \mathrm{E}$ and $32^{\circ} 12^{\prime} 11^{\prime \prime} \mathrm{N}-35^{\circ} 48^{\prime} 7^{\prime \prime} \mathrm{N}$ (Fig. 1). It covers an area of $121972 \mathrm{~km}^{2}$ (15\% of the whole Yellow River basin), characterized by highly variable topographic structure ranging from $6282 \mathrm{~m}$ a.s.l. in the Anyemqen Mountains in the west to $2546 \mathrm{~m}$ a.s.l. in the village of Tangnag in the east, which strongly influences the spatial variability of the local climate (Hu et al., 2011, 2012, 2013). The study area has a cold, semi-humid climate, characterized by the typical QinghaiTibetan Plateau climate system. The climate in this region is strongly governed by the Asian monsoon, which brings moist, warm air in the summer and dry, cool air during the winter (Lan et al., 2010). Annual average daily temperature varies between -4 and $2{ }^{\circ} \mathrm{C}$ from the southeast to the northeast. July is the warmest month, with a mean daily temperature of $8{ }^{\circ} \mathrm{C}$. From October to April the temperature remains well below $0{ }^{\circ} \mathrm{C}$.

\subsection{Data set}

\subsubsection{Observed station data}

Daily maximum and minimum temperature from 13 stations sparsely distributed throughout the study region, for the period 1961-1990 were used in this study. Figure 1 depicts the geographical location of the stations in the study region and Table 1 shows their latitude, longitude and altitude. 
Table 1. Geographical characteristics of the climatic stations used in this study.

\begin{tabular}{lcrc}
\hline Name & $\begin{array}{r}\text { Latitude } \\
\left({ }^{\circ} \mathrm{N}\right)\end{array}$ & $\begin{array}{r}\text { Longitude } \\
\left({ }^{\circ} \mathrm{E}\right)\end{array}$ & $\begin{array}{r}\text { Altitude } \\
(\mathrm{m})\end{array}$ \\
\hline Qingshuihe & 33.80 & 97.13 & 4418 \\
Maduo & 34.92 & 98.22 & 4272 \\
Qumalai & 34.13 & 95.78 & 4231 \\
Renxiamu & 34.27 & 99.20 & 4211 \\
Dari & 33.75 & 99.65 & 3968 \\
Zeku & 35.03 & 101.47 & 3663 \\
Jiuzhi & 33.43 & 101.48 & 3628 \\
Henan & 34.73 & 101.60 & 3500 \\
Hongyuan & 32.80 & 102.55 & 3491 \\
Ruoergai & 33.58 & 102.97 & 3439 \\
Maqu & 33.97 & 102.08 & 3400 \\
Tongde & 35.27 & 100.65 & 3289 \\
Xinghai & 35.58 & 99.98 & 3245 \\
\hline
\end{tabular}

Slightly less than $0.0017 \%$ of the data from two stations were missing, which were infilled using the records from neighboring stations. The double mass curve method was applied to test the homogeneity of the data set by plotting the monthly value from the station against the mean values (monthly) of all other stations (Hu et al., 2012). According to the results of the test, all the data were found homogeneous.

\subsubsection{Reanalysis data}

In addition to the observed data, large-scale atmospheric predictors derived from the National Center for Environmental Prediction/National Centre for Atmospheric Research (NCEP/NCAR) reanalysis data set (Kalnay et al., 1996) on a $2.5^{\circ} \times 2.5^{\circ}$ grid over the same time period as the observation data were employed for calibration and validation of the statistical downscaling models. These variables include specific humidity, air temperature, zonal and meridional wind speeds at various pressure levels and mean sea level pressure.

\subsubsection{GCM data}

In order to project future scenarios, outputs from two GCMs under the Intergovernmental Panel on Climate Change Special Report on Emissions Scenarios (IPCC-SRES) A2 (highrange emission), A1B (mid-range emission) and B1 (lowrange emission) were used: (1) the Canadian Center for Climate Modelling and Analysis (CCCma) 3rd Generation (CGCM3.1 (T47)), and (2) the ECHAM5/MPI-OM GCM from the Max-Planck-Institute for Meteorology, Germany (hereafter ECHAM5). Both models are coupled atmosphereocean models. CGCM3 has a horizontal resolution of T47 (approximately $3.75^{\circ}$ latitude $\times 3.75^{\circ}$ longitude) and 32 vertical levels. ECHAM5 has a horizontal resolution of T63 (approximately $1.875^{\circ}$ latitude $\times 1.875^{\circ}$ longitude) and 31 vertical levels. Those two GCMs were selected on the basis of (i) their relatively reasonable performances in simulating the 20th century surface air temperature over China (Zhou and Yu, 2006; Wang et al., 2013) and the South Asian summer monsoon over the historical period (Fan et al., 2010) and (ii) their wide use in previously conducted climate change studies. These GCM data are obtained from the Program for Climate Model Diagnosis and Intercomparison (PCMDI) website (http://www-pcmdi.llnl.gov). The A2, A1B and B1 scenarios span almost the entire IPCC scenario range, with the $\mathrm{B} 1$ being close to the low end of the range, the $\mathrm{A} 2$ to the high end of the range and $\mathrm{A} 1 \mathrm{~B}$ to the middle of the range. The GCM simulations corresponding to the present (1961-1990) and two future climates (2046-2065 and 20812100) were considered in the analysis. Prior to use in this study, both GCMs grids were linearly interpolated to the same $2.5^{\circ} \times 2.5^{\circ}$ grids fitting the NCEP reanalysis data.

\section{Methodology}

\subsection{Temperature indices}

To represent extreme temperature conditions (both the frequency and intensity of temperature extremes), eight temperature indices, including two indices for mean minimum and maximum temperature, are selected. The indices included in this study are:

1. mean $T_{\max }$ (Txav) - mean daily maximum temperature $\left[{ }^{\circ} \mathrm{C}\right]$

2. mean $T_{\min }$ (Tnav) - mean daily minimum temperature $\left[{ }^{\circ} \mathrm{C}\right]$

3. diurnal temperature range (DTR) - difference between daily maximum and minimum temperature $\left[{ }^{\circ} \mathrm{C}\right]$;

4. hot day (Txq90) - 90th percentile value of daily maximum temperature in a year $\left[{ }^{\circ} \mathrm{C}\right]$;

5. cold day (Tnq10) - 10th percentile value of daily minimum temperature in a year $\left[{ }^{\circ} \mathrm{C}\right]$;

6. frequency of hot days (Tx90p) - the percentage of time in a year when daily maximum temperature is above the 90th percentile of the 1961-1990 daily maximum temperature distribution [\%];

7. frequency of warm nights $(\operatorname{Tn} 90 \mathrm{p})$ - the percentage of time in a year when daily minimum temperature is above the 90th percentile of the 1961-1990 daily minimum temperature distribution [\%];

8. frost days (Tnfd) - the number of days with daily minimum temperature $<0^{\circ} \mathrm{C}$ [days].

Each of the indices has been calculated for 1961-1990 (present period) and 2081-2100 (future period), and for three scenarios A2, A1B and B1. Except for the frost days, all 
of the indices have been analyzed for four seasons, which are defined as winter (December-February, DJF), spring (March-May, MAM), summer (June-August, JJA) and autumn (September-November, SON). Frost days are not analyzed for winter since it has little meaning for the study region in winter where the daily minimum temperature is around $20^{\circ} \mathrm{C}$ below zero.

\subsection{Choice of predictors}

In this study the predictors were first selected taking into consideration the monsoon climate formulation mechanism. Atmospheric circulation and moisture strongly influence the monsoon climate. The monsoon climate in the study region is caused by the temperature difference between land and sea, which brings cold, dry air from the northwest in winter and warm, moist air from the Bay of Bengal and the western Pacific Ocean in summer (Lan et al., 2010). Sea level pressure, geo-potential height, air temperature, wind speed and humidity are often used for downscaling surface air temperature (Anandhi et al., 2009; Chen and Chen, 2003; Wilby et al., 2002). On the basis of the results of earlier downscaling studies, a number of atmospheric variables were taken as the potential predictors including air temperature, specific humidity, zonal and meridional wind at various pressure levels and mean sea level pressure. Unfortunately the geo-potential height was not taken as the potential predictor since the GCM dataset of this variable is not available from the Program for Climate Model Diagnosis and Intercomparison (PCMDI) website. These potential predictors were then screened through a correlation analysis with daily maximum (minimum) temperature at each of the 13 stations. Furthermore, experiences and recommendations from similar studies in China and neighboring regions were also taken into account (Anandhi et al., 2009; Chu et al., 2010; Wang et al., 2012). Similar methods were used by $\mathrm{Hu}$ et al. (2013) to select predictors for downscaling daily precipitation over this region. The final set of predictors for downscaling $T_{\max }$ and $T_{\min }$ was selected as follows: specific humidity at 700 , 850 and $1000 \mathrm{hPa}$ level and air temperature at 500, 700, 850 and $1000 \mathrm{hPa}$ level. The explanatory power of a given predictor will vary both spatially and temporally for a given predictand. The use of predictors directly overlying the target grid box will likely fail to capture the strongest correlation (between predictor and predictand), as this domain may be geographically smaller in extent than the circulation domains of the predictors (Wilby and Wigley, 2000). Selecting the spatial domain of the predictors is subjective to the predictor, predictand, season and geographical location (Anandhi et al., 2009). On the basis of these recommendations and monsoon climate generation mechanism, the predictor domain in this study extends from $30^{\circ} \mathrm{N}$ to $40^{\circ} \mathrm{N}$ and from $92.5^{\circ} \mathrm{E}$ to $107.5^{\circ} \mathrm{E}$ covering the entire study region (Fig. 1).

The predictors were first standardized at each grid point by subtracting the mean and dividing by the standard deviation.
A principal component analysis (PCA) was then performed to reduce the dimensionality of the predictors. The first eight principal components (PCs), which account for more than $90 \%$ of the total variance, were then used as input to the downscaling model. The principal components were selected on the basis of the percentage of variance of original data explained by individual principal component. This criterion was also used by Ghosh (2010) and Hu et al. (2013). Note that other methods also exist for selecting the principal components, e.g. the elbow method used by Wetterhall et al. (2006).

\subsection{Statistical downscaling model (SDSM)}

The SDSM is a decision support tool developed by Wilby et al. (2002) for assessing local climate change impacts. The SDSM algorithm is best described as a conditional weather generator in which large-scale predictors are used to linearly condition local-scale weather generator parameters (e.g. precipitation occurrence or maximum temperature) at individual stations (Wilby et al., 2003; Wilby and Dawson, 2013). For temperature the downscaled process is unconditional, i.e. there is a direct linear relationship between the predictand (i.e. temperature) and the chosen predictors. SDSM employs bias correction and variance inflation to adjust the mean and variance of downscaled variables to match the observed ones. For a detailed model description, see Wilby et al. (2003) and Wilby and Dawson (2013). SDSM has been applied to produce high-resolution climate change scenarios in a range of geographical contexts (Wetterhall et al., 2006; Chu et al., 2010; Wang et al., 2012; Hu et al., 2013; J. S. Yang et al., 2012).

\section{Results and discussion}

\subsection{Validation of the statistical downscaling model (validation period 1981-1990)}

The standard split-sampling technique of model calibration and validation was implemented in this work. The model calibration was performed for the period 1961-1980, while the period 1981-1990 was used for validation. As the SDSM is a stochastic model, 100 realizations of daily maximum (minimum) temperature are generated, and the indices are calculated as the average of the indices calculated from each realization. We also tested the sensitivity by using a larger number of realizations (e.g. 200, 300, 400 and 500) but found no significant changes in the results. The skill of the downscaling model to reproduce the mean and extreme temperature is evaluated and compared in terms of the Spearman's rank correlation coefficient and the bias between the simulated and observed indices. Model evaluation was performed on a monthly basis.

Figure 2 shows the correlation coefficients and the differences between the simulated and observed indices (mean 

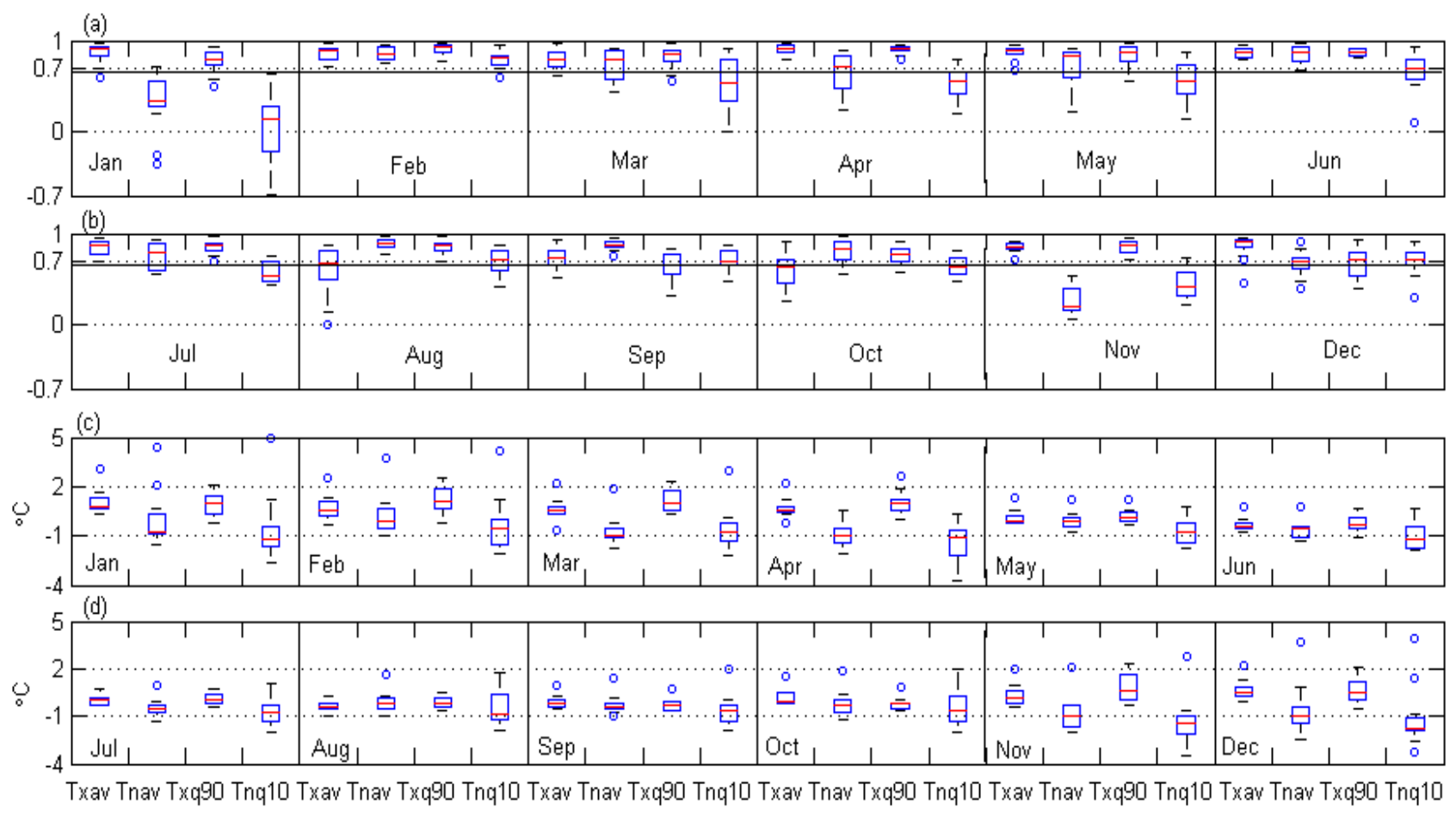

Fig. 2. Correlations (a-b) and differences $(\mathbf{c}-\mathbf{d})$ between the simulated and the observed extreme temperature indices for each month during the validation period 1981-1990. The whisker-box plots depict the range of the correlation across 13 stations. The boxes denote the median and interquartile range (IQR). Whiskers extend 1.5 IQR from box ends, with outliers denoted as circles. The horizontal solid line denotes significant correlation at the $5 \%$ confidence level.

maximum and minimum temperature, 90th percentile of the maximum temperature, and 10th percentile of minimum temperature) for each month. The whisker-box plots show spatial variability of the correlations and the bias across all the stations. The horizontal solid line in Fig. 2a-b shows the value of the correlation coefficient above which they are statistically significant ( $95 \%$ confidence level). As can be seen from these plots, the model simulates the mean and the 90th percentile of daily maximum temperature (Txav, Txq90) very well with the majority of the stations showing statistically significant correlations and relatively lower biases in almost all months. However, a relatively poor performance in simulating Txav in August and October and Txq90 in September and December is observed. The mean minimum temperature (Tnav) is also well reproduced by the models in most months with the exception of the winter months from November to January. The model performance is generally poor for the 10th percentile of daily minimum temperature (Tnq10) where most stations show insignificant correlations and large bias in most months. Generally, the model shows more skill for the maximum temperature-related indices (Txav, Txq90) than for the minimum temperature-related indices (Tnav, Tnq10). A comparison between different months reveals that in general the temperature indices were better downscaled for the summer months than for other months. Such a seasonal dependence of downscaling skill was also found in other parts of the world (e.g. Haylock et al., 2006 in England; Wetterhall et al., 2007 in Sweden; Hundecha and Bárdossy, 2008 in German). This may relate to the fact that the local climate of the study region in summer is largely determined by large-scale circulation (e.g. summer monsoon) while it is mainly determined by local convective processes in other seasons.

\subsection{Downscaling for the current climate (1961-1990)}

The downscaling model calibrated and validated using the NCEP predictors was forced by the two GCMs outputs for the present climate (1961-1990) to evaluate whether the downscaled temperature indices from the two GCMs can reproduce the variability of the observed ones. Figure 3 depicts the difference between the downscaled and observed temperature indices (Txav, Tnav, Txq90, Tnq10) for each station and each season. Overall, the downscaled results from both GCMs are able to reproduce the observed temperature indices reasonably well with the bias generally varying between -2 and $2{ }^{\circ} \mathrm{C}$ across different stations in all seasons with a few exceptions in winter and autumn. The biases in the downscaled temperature indices are of similar magnitude for the two GCMs, and no systematic and notable differences are found. 

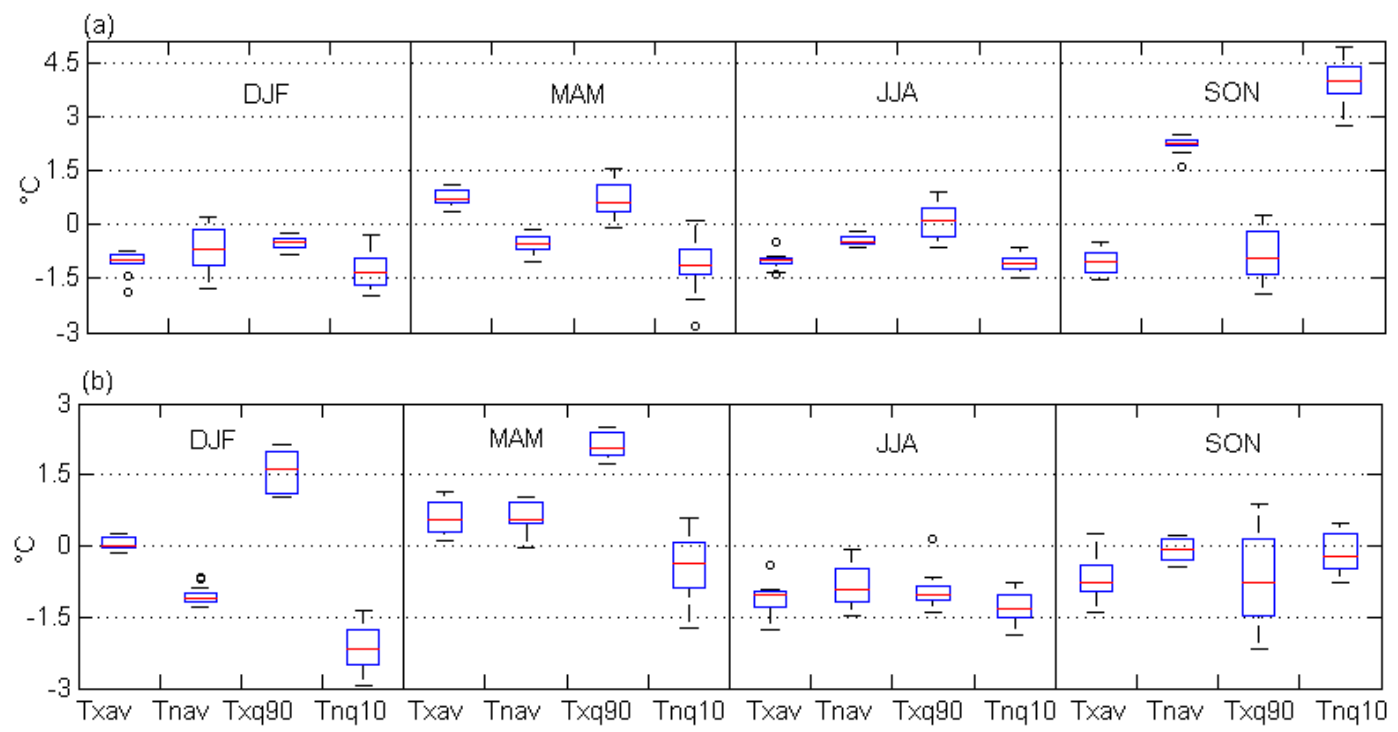

Fig. 3. Biases of the extreme temperature indices downscaled from the CGCM3 (a) and the ECHAM5 predictors (b) for the four seasons during the control period 1961-1990. The whisker-box plots depict the range of the bias across 13 stations. The boxes denote the median and interquartile range (IQR). Whiskers extend 1.5 IQR from box ends, with outliers denoted as circles.

\subsection{Future projections (2046-2065 and 2081-2100)}

The statistical downscaling model (calibrated) is used to downscale daily maximum and minimum temperature from two GCMs for three emission scenarios. Estimated changes in the mean of selected temperature indices for the two future periods (2046-2065 and 2081-2100) are investigated against the control period (1961-1990). The changes in the mean correspond to the difference between mean values of each index in the future period and those in the control period. A two-tailed Student's $t$ test for the 5\% confidence level is performed to check if the mean values from the present and future periods are significantly different. Also, we have analyzed elevation dependency of the projected changes for each index. Figures 4-7 illustrate the projected climate change of each index with station altitude. A one-tailed Student's $t$ test for the $5 \%$ confidence level is performed to check if the linear trends of the projected changes with increasing altitude are statistically significant.

\subsubsection{Projected changes in the mean state of the temperature indices}

All the temperature indices, with the exception of the DTR, show statistically significant warming at all stations in all future seasons with both GCMs and three emission scenarios (Figs. 4-7). By the middle and end of the 21st century, all parts of the study region are expected to experience statistically significant increases in the intensity of both mean and extreme temperature, together with significant increases in the occurrence of hot days and warm nights and with decreases in frost days. As expected, the projected changes in the temperature indices for 2081-2100 are generally larger than those for 2046-2065. The accelerated warming suggested by these results may be due to the strong greenhouse forcing toward the end of the 21st century. While there is strong agreement in the direction of projected changes, the magnitude of the changes varies between different GCMs and emission scenarios. The effect of the driving GCM on the magnitude of estimated changes in 2081-2100 is evident in Figs. 6 and 7, with the ECHAM5-driven projections showing larger changes in the temperature indices than the CGCM3-driven ones. Also, we note that the projected changes in 2081-2100 tend to scale with the emission scenario, i.e. the larger the greenhouse gas forcing, the stronger the response (generally most intense in the A2, followed by the A1B and B1 scenarios). However, the same does not hold true in 2046-2065, where no systematic differences in the magnitude of the projected changes from two GCMs are noticed (Figs. 4 and 5). Unlike the end of the 21st century, we note that in some cases the projected changes for the middle of the 21 st century are stronger in the A1B scenario than in the A2 scenario. This is particularly noticeable in the ECHAM5-driven projections. This is probably due to the following reason: although the $\mathrm{CO}_{2}$ concentrations are similar in $\mathrm{A} 1 \mathrm{~B}$ and $\mathrm{A} 2$ emission scenarios up to the middle of the 21st century, the A2 scenario specifies somewhat greater sulphate aerosol concentrations, which are thought to have a cooling effect on surface temperature (Ramanathan et al., 2001). For both the future periods, we see a similar and pronounced seasonality of projected changes. For the intensityrelated indices, the mean maximum temperature and hot day (Txav, Txq90; Figs. 4a and $\mathrm{b}$ and $6 \mathrm{a}$ and $\mathrm{b}$ ) show the largest warming in winter and the least one in summer, while the 

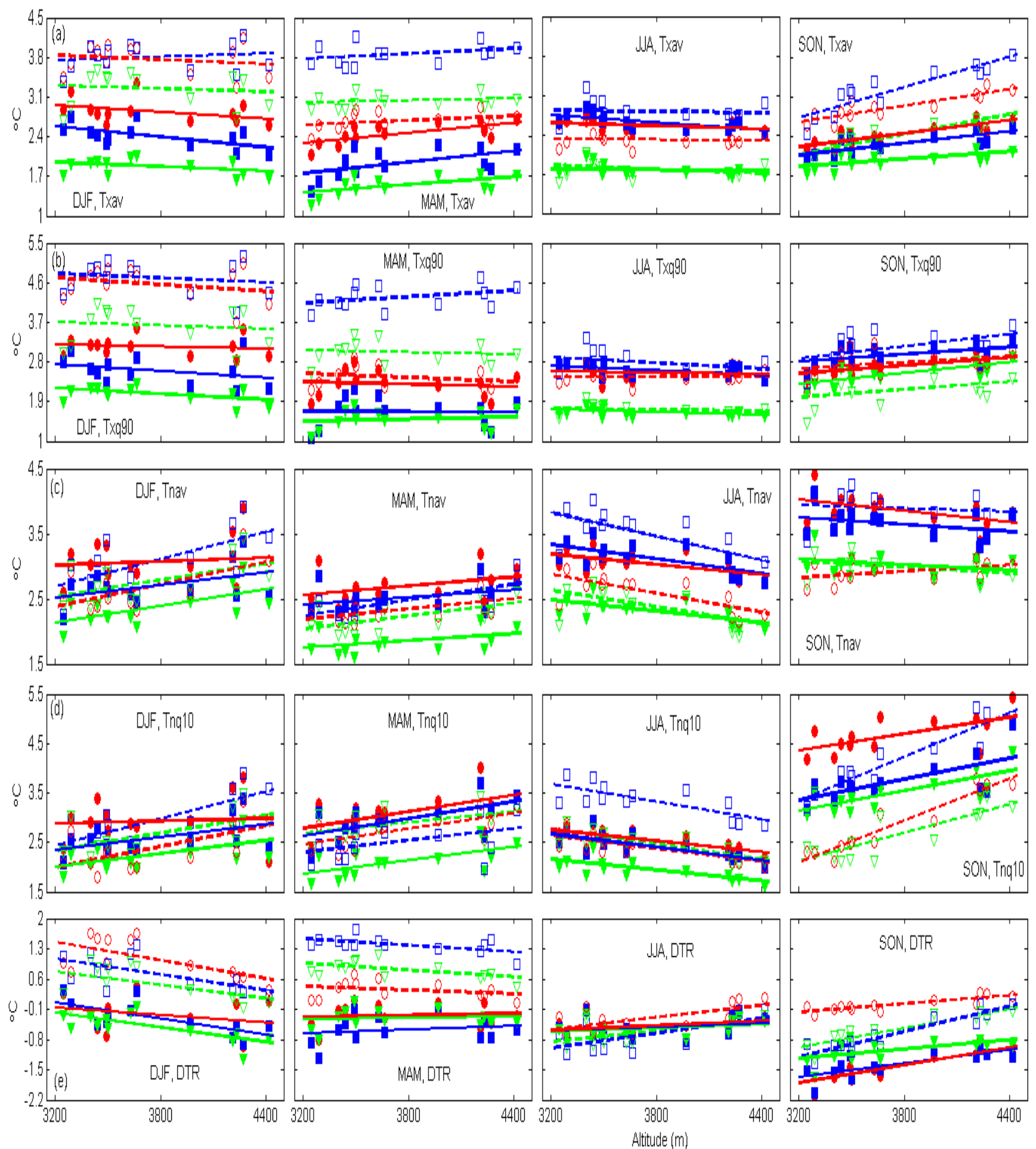

- CGCM3-A2 \ CGCM3-A1B V CGCM3-B1 O ECHAM5-A2 $\square$ ECHAM5-A1B $\nabla$ ECHAM5-B1

Fig. 4. Projected anomalies of the intensity-related indices (between 2046-2065 and 1961-1990) with station altitude for four seasons based on statistical downscaling outputs of two GCMs (CGCM3 and ECHAM5) under three emission scenarios (A2, A1B and B1). 

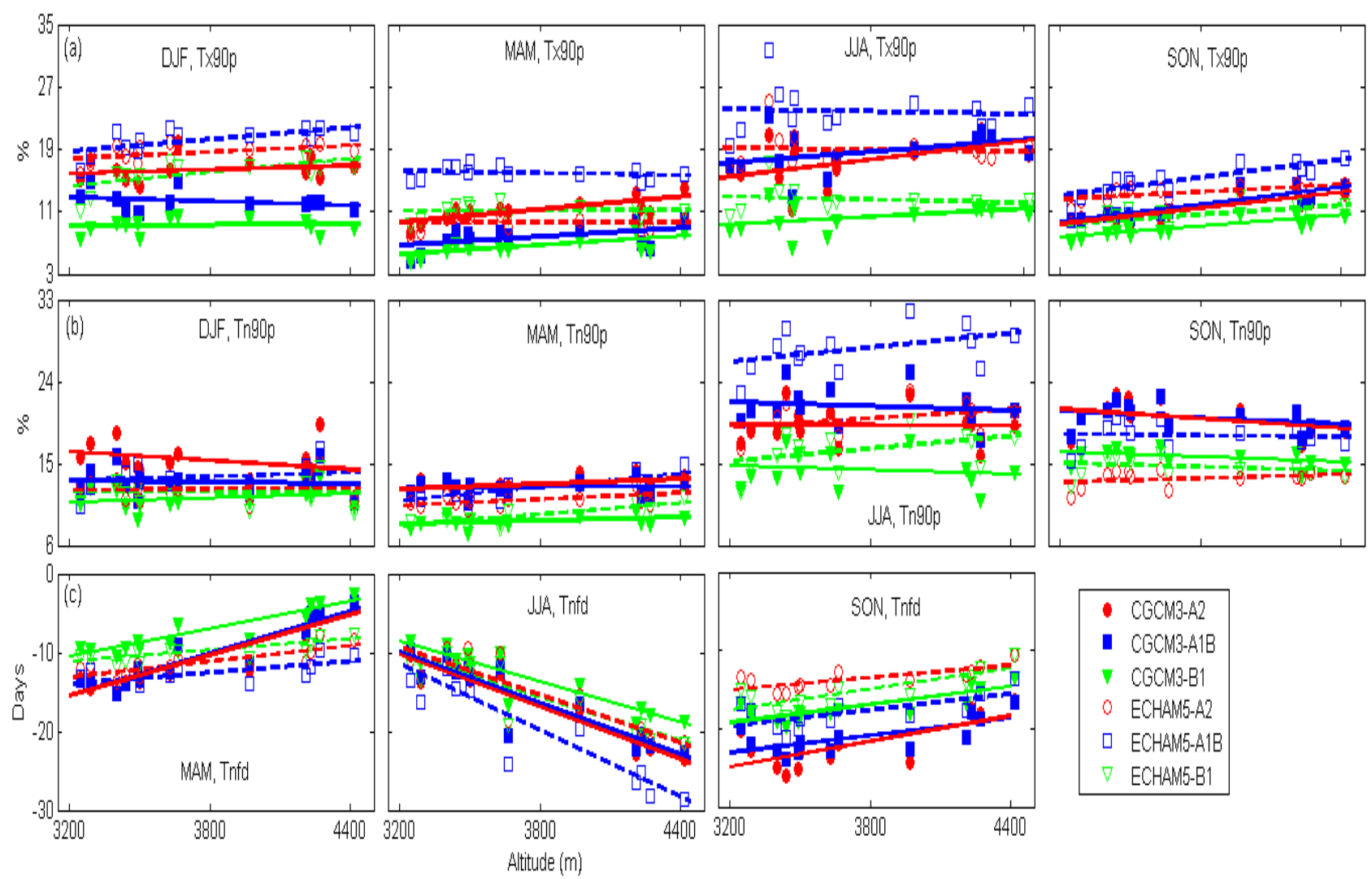

Fig. 5. As in Fig. 4, but for the frequency-related indices.

mean minimum temperature and cold night (Tnav, Tnq10; Figs. $4 \mathrm{c}$ and $\mathrm{d}$ and $6 \mathrm{c}$ and d) show the largest warming in autumn and the least one in spring, which is partly consistent with recent observations over the study region and the Tibetan Plateau, where winter was reported to have the largest warming rate, followed by autumn (Hu et al., 2012; Liu and Chen, 2000; Liu et al., 2006; Rangwala et al., 2009; Zhang et al., 2008). However, note that there are some discrepancies in the seasonality of projected warming as reported in different studies, which is probably due to choice of different GCMs. For example, using the same downscaling model (SDSM) but with a different GCM (HadCM3), Wang et al. (2012) found that Txav and Tnav is expected to undergo the largest warming in autumn and summer, respectively, during the period 2070-2099 under the A2 and B2 scenarios. Using several GCMs (CGCM2, CCSR, CSIRO and HadCM3), Xu et al. (2009) reported that Txav (Tnav) would experience greater warming in spring and autumn (summer and autumn) under the B2 scenario. Compared to other temperature indices, projected changes in diurnal temperature range (DTR) are less strong and less consistent. DTR is expected to experience a significant decrease in summer and autumn, indicating a greater warming in minimum temperature than in maximum temperature, consistent with recent observational studies over this region and its vicinity $(\mathrm{Hu}$ et al., 2012a; Liu et al., 2006; You et al., 2008). However, changes in DTR are ambiguous in winter and spring with the CGCM3-driven projections showing non-significant decreases and the ECHAM5-driven ones significant increases. As for the frequency-related indices (Figs. 5 and 7), the occurrences of hot days and warm nights show the largest increases in summer and the least ones in spring, while frost days show the largest decrease in summer and autumn. Under the same emission scenarios, T. Yang et al. (2012) reported similar findings for the frost days and the frequency of warm nights over the entire Tibetan Plateau for the 21st century based on multi-model ensemble projections.

\subsubsection{Elevation dependency of the projected changes in the temperature indices}

As displayed in Figs. 4a and 6a, the projected warming in autumn Txav shows a statistically significant increasing trend with altitude in the two future periods, with a varying rate of $0.2-0.9^{\circ} \mathrm{C}$ per $\mathrm{km}$ for $2046-2065$ and $0.48-1.1^{\circ} \mathrm{C}$ per $\mathrm{km}$ for 2081-2100, respectively. A similar tendency is found in spring, but only the trends based on the CGCM3 projections are statistically significant. As in the case of Txav, there is also a pronounced elevation dependency in projected warming in autumn Txq90 in the period 2081-2100 but at a 

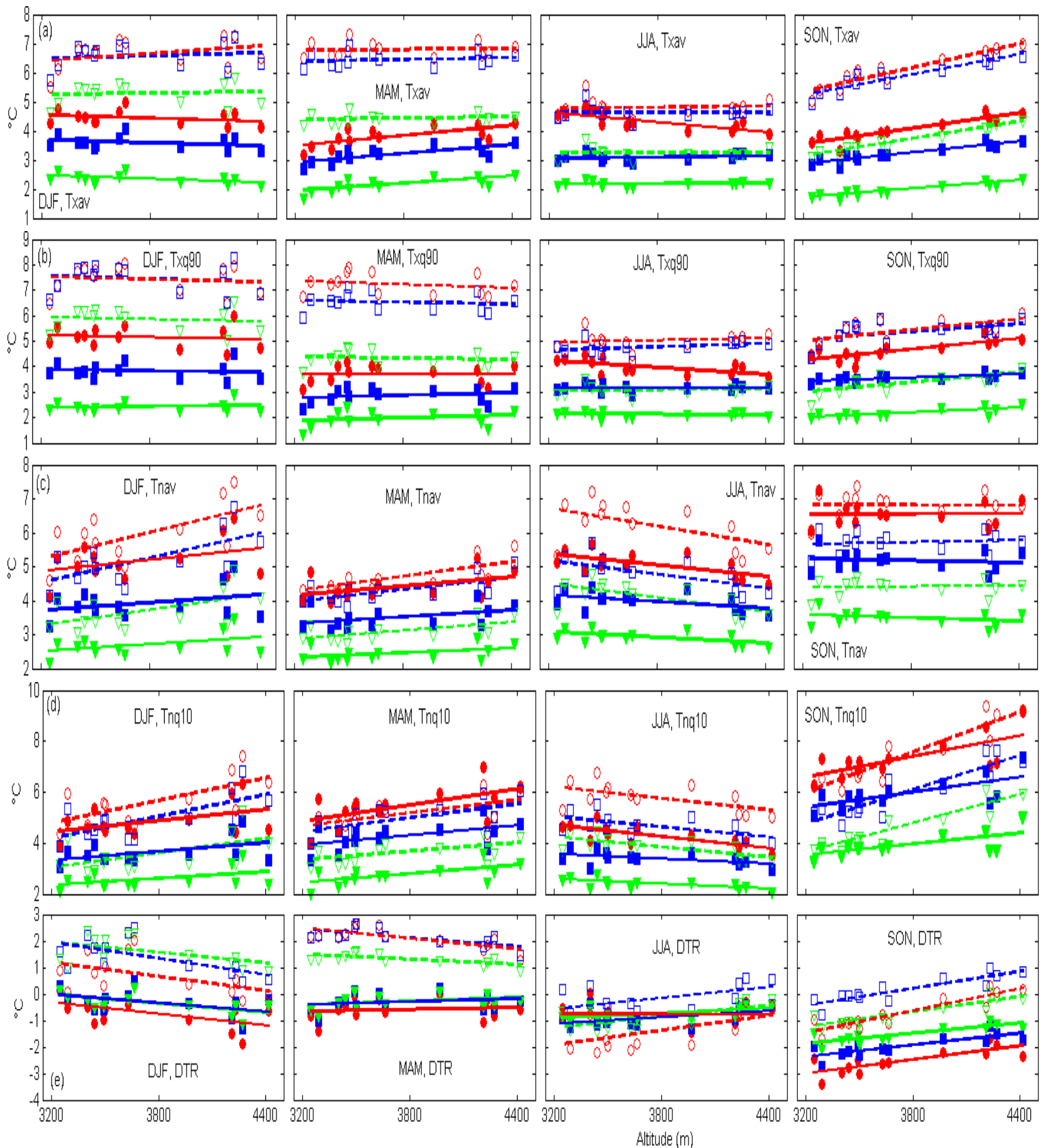

- CGCM3-A2 \ CGCM3-A1B $\nabla$ CGCM3-B1 O ECHAM5-A2 $\quad$ ECHAM5-A1B $\nabla$ ECHAM5-B1

Fig. 6. Projected anomalies of the intensity-related indices (between 2081-2100 and 1961-1990) with station altitude for four seasons based on statistical downscaling outputs of two GCMs (CGCM3 and ECHAM5) under three emission scenarios (A2, A1B and B1).

lesser rate $\left(0.23-0.73{ }^{\circ} \mathrm{C}\right.$ per $\left.\mathrm{km}\right)$ (Fig. 6b). A similar tendency is observed for autumn Txq90 in the period 20462065 but insignificant in most cases. For Tnav in summer (Figs. 4c and 6c), a significant decreasing warming with altitude is noted with a rate ranging from 0.26 to $0.61{ }^{\circ} \mathrm{C}$ per $\mathrm{km}$ for $2046-2065$ and 0.28 to $0.69^{\circ} \mathrm{C}$ per $\mathrm{km}$ for $2081-$ 2100 . In contrast, winter and spring demonstrate increasing warming with altitude for the two future periods, but only the trends based on the ECHAM5 projections reach the significance level. The results reported here are in overall 

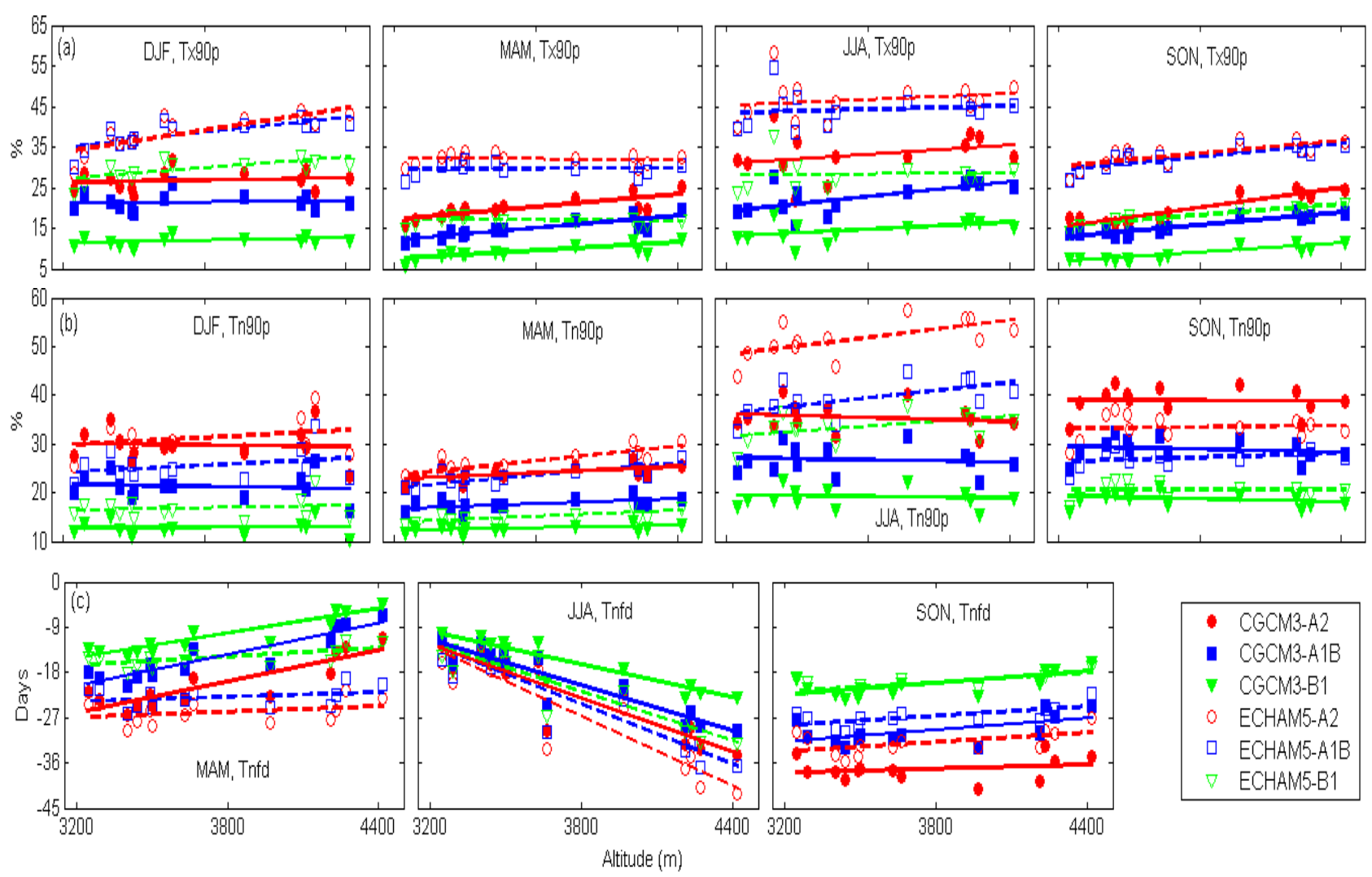

Fig. 7. As in Fig. 6, but for the frequency-related indices.

agreement with the findings obtained by Xu et al. (2009) over the Tibetan Plateau, suggesting elevation-dependent warming in Tnav in all seasons other than summer for the end of the 21 st century under the A1B scenario. Similar to Tnav, future warming in summer Tnq10 suggests a significant decreasing trend with elevation (Figs. $4 \mathrm{~d}$ and $6 \mathrm{~d}$ ). This is in clear contrast to other seasons, in particular to autumn, where a strong elevation-dependent warming demonstrates with a much larger rate of $0.55-1.48^{\circ} \mathrm{C}$ per $\mathrm{km}$ for $2046-2065$ and $0.72-2.6^{\circ} \mathrm{C}$ per $\mathrm{km}$ for $2081-2100$. Concerning DTR (Figs. $4 \mathrm{e}$ and $6 \mathrm{e}$ ), it is unexpected to see that future reductions in this index during autumn show a significant weakening tendency with altitude. Similar results are projected for summer, but only the trends based on the ECHAM5 projections reach the significance level. Future increases in autumn Tx90p show a significant increasing trend with elevation (Figs. 5a and 7a). A similar trend is also projected for Tx90p in winter with the ECHAM5-driven projections and in spring with the CGCM3-driven projections. Projected increases in spring Tn90p in 2081-2100 show a significant increasing trend with elevation. Similar trends are noted for spring Tn90p in 2046-2065, but only the trends based on the ECHAM5 projections are statistically significant. Regarding future reductions in frost days (Fig. $5 \mathrm{c}$ and $7 \mathrm{c}$ ), note that summer shows a strong enhanced decrease with elevation at a rate of 8-14 days per $\mathrm{km}$ for 2046-2065 and 10-23 days per km for 2081-2100 while spring and autumn show an opposite trend at a lesser rate.

In general, the two future periods show similar elevationdependent changes with the rate of the projected changes, with altitude being stronger in 2081-2100 than in 20462065. The indices related to the minimum temperature demonstrate more pronounced elevation-dependent changes than the indices related to the maximum temperature. In comparison to other seasons, autumn shows pronounced elevation-dependent changes in which around six out of eight indices show significant increasing changes with elevation. By investigating trends on the observed data from the latter half of the 20th century over the same region, Hu et al. (2012) also showed more pronounced elevation-dependent changes in the indices related to the minimum temperature. However, in their study winter season indices showed more pronounced elevation-dependent changes than other seasons.

\subsubsection{Projected changes in interannual variability of the temperature indices}

The analysis of changes in interannual variability of each index has been done by applying an $F$ test on the variance of estimated Probability Density Functions (PDFs) of the future and control periods at the $5 \%$ level. For the period 

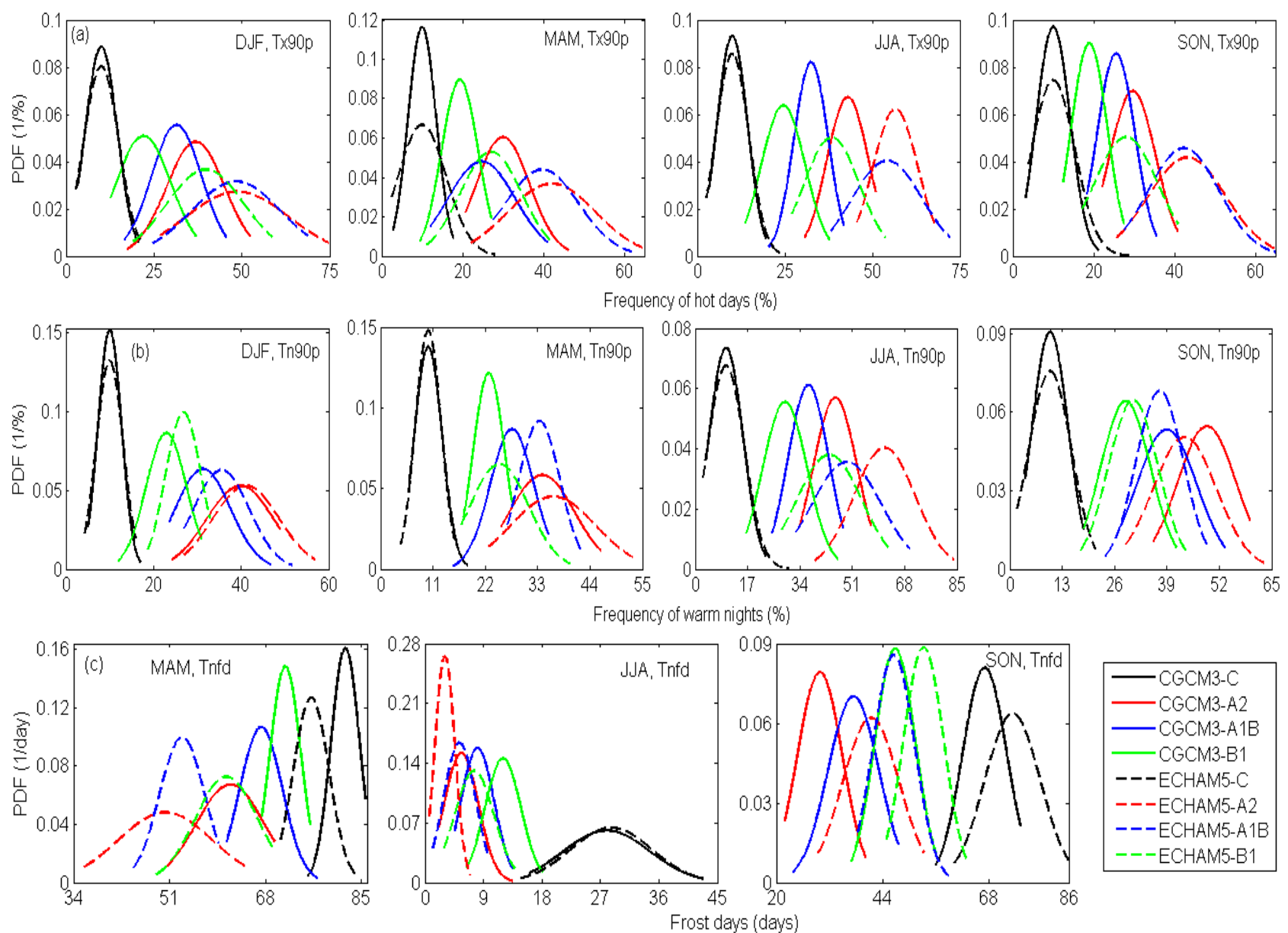

Fig. 8. Fitted normal probability density functions (PDFs) of the frequency-related indices averaged across stations for 2081-2100 and 19611990 for four seasons based on statistical downscaling outputs of two GCMs (CGCM3 and ECHAM5) under three emission scenarios (A2, A1B, B1).

2046-2065, the future PDFs of all the indices show insignificant changes in the shape in all seasons in comparison to a substantial shift of the mean (not shown). Similar results were obtained for the intensity-related indices in the period 2081-2100 (not shown). However, the same is not true in the case of the frequency-related indices in 2081-2100, where the future PDFs show a large shift of the mean as well as significant changes in the shape (Fig. 8). By the end of the 21st century, the future PDFs of the frequency-related indices become wider and flatter in all seasons for the occurrence of hot days and warm nights and for frost days in spring while they become narrower and sharper for frost days in summer. This suggests that by the end of the 21 st century the interannual variability of the occurrence of hot days and warm nights might increase in all seasons while that of frost days might decrease in summers and increase in springs.

\section{Conclusions}

This study presents projections of possible changes in mean and extreme temperature indices and their elevation dependency over the Yellow River source region for the two future periods 2046-2065 and 2081-2100 (relative to 19611990) under the SRES A2, A1B and B1 emissions scenarios. The projections are performed using the Statistical DownScaling Models (SDSM) to downscale the outputs of two GCMs (CGCM3 and ECHAM5). Validation results using the NCEP/NCAR reanalysis show that SDSM performs better in reproducing the maximum temperature-related indices than the minimum temperature-related ones. When driven by the GCMs outputs corresponding to the control period 19611990, the downscaled temperature indices are able to reproduce the observed ones reasonably well with the two GCMs showing similar bias.

For the middle and end of the 21st century, all parts of the study region are expected to undergo significant increases in the intensity of mean and extreme temperature in all seasons, 
along with significant increases in the frequency of hot days and warm nights and with decreases in frost days. As expected, the projected changes in the temperature indices in 2081-2100 are generally larger than those in 2046-2065. Compared to other indices, changes in diurnal temperature range are less significant and less consistent in winter and spring. Diurnal temperature range is expected to experience a significant decrease in summer and autumn, indicating a greater warming in minimum temperature than in maximum temperature. The two future periods show similar elevationdependent changes with the rate of the projected changes with altitude being stronger in 2081-2100 than in 20462065. Many of the indices demonstrate elevation-dependent changes, which varies from index to index and from season to season. All the intensity-related indices show a significant increasing warming with elevation in autumn with the exception of Tnav. In contrast, projected warming in Tnav and Tnq10 in summer displays a significant decreasing trend with elevation. Projected increases in hot days and warm nights show a significant increasing trend with elevation in autumn and spring, respectively. A similar trend is also found for reductions in frost days in summer. However, reductions in frost days tend to decrease with elevation in spring and autumn, with the majority of the projections reaching the significance level. Along with a large shift of the mean, significant changes in the shape of the future PDFs are also observed for the frequency-related indices in 2081-2100, indicating significant changes in interannual variability. By the end of the 21 st century, the frequency of hot days and warm nights is likely to experience significant increasing in interannual variability in all seasons under the considered future scenarios. Frost days are expected to experience significant decreasing in interannual variability in summers and increasing one in springs.

Acknowledgements. This study was jointly supported by UNESCO-IHE Institute for Water Education, Rijkswaterstaat (the Ministry of Transport, Public Works and Water Management), Netherlands, and Yellow River Conservancy Commission, China. The authors acknowledge the modelling groups, the Program for Climate Model Diagnosis and Intercomparison (PCMDI) and the WCRP's Working Group on Coupled Modelling (WGCM) for their roles in making the WCRP CMIP3 multi-model data set available. The WCRP CMIP3 multi-model data set is supported by the Office of Science, US Department of Energy.

Edited by: A. Opere

\section{References}

Anandhi, A., Srinivas, V. V., Nagesh Kumar, D., and Nanjundiah, R. S.: Role of predictors in downscaling surface temperature to river basin in India for IPCC SRES scenarios using support vector machine, Int. J. Climatol. 29, 583-603, doi:10.1002/joc.1719, 2009.

Beniston, M. and Rebetez, M.: Regional behavior of minimum temperatures in Switzerland for the period 1979-1993, Theor. Appl. Climatol., 53, 231-243, 1996.

Beniston, M., Diaz, H., and Bradley, R.: Climatic change at high elevation sites: an overview, Climatic Change, 36, 233-251, 1997.

Chen, B., Chao, W., and Liu, X.: Enhanced climatic warming in the Tibetan Plateau due to doubling $\mathrm{CO}_{2}$ : a model study, Clim. Dynam., 20, 401-413, 2003.

Chen, D. and Chen, Y.: Association between winter temperature in China and upper air circulation over East Asia revealed by canonical correlation analysis, Global Planet. Change, 37, 315-325, 2003.

Chu, J., Xia, J., Xu, C., and Singh, V.: Statistical downscaling of daily mean temperature, pan evaporation and precipitation for climate change scenarios in Haihe River, China, Theor. Appl. Climatol., 99, 149-161, doi:10.1007/s00704-009-0129-6, 2010.

Diaz, H. F. and Bradley, R. S.: Temperature variations during the last century at high elevation sites, Climatic Change, 36, 253279, 1997.

Diaz, H. F. and Eischeid, J. K.: Disappearing 'alpine tundra' Köppen climatic type in the western United States, Geophys. Res. Lett., 34, L18707, doi:10.1029/2007GL031253, 2007.

Fan, F., Mann, M. E., Lee, S., and Evans, J. L.: Observed and modeled changes in the South Asian Summer Monsoon over the historical period, J. Climate, 23, 5193-5205, 2010.

Fischer, E. and Schär, C.: Future changes in daily summer temperature variability: driving processes and role for temperature extremes, Clim. Dynam., 33, 917-935, 2009.

Giorgi, F.: Climate change hot-spots, Geophys. Res. Lett., 33, L08707, doi:10.1029/2006GL025734, 2006.

Giorgi, F., Hurrell, J., Marinucci, M., and Beniston, M.: Elevation dependency of the surface climate change signal: a model study, J. Climate, 10, 288-296, 1997.

Ghosh, S.: SVM-PGSL coupled approach for statistical downscaling to predict rainfall from GCM output, J. Geophys. Res., 115, D22102, doi:10.1029/2009JD013548, 2010.

Haylock, M. R., Cawley, G. C., Harpham, C., Wilby, R. L., and Goodess, C. M.: Downscaling heavy precipitation over the United Kingdom: a comparison of dynamical and statistical methods and their future scenarios, Int. J. Climatol., 26, 13971415, doi:10.1002/joc.1318, 2006.

Hu, Y., Maskey, S., Uhlenbrook, S., and Zhao, H.: Streamflow trends and climate linkages in the source region of the Yellow River, China, Hydrol. Process., 25, 3399-3411, doi:10.1002/hyp.8069, 2011.

$\mathrm{Hu}$, Y., Maskey, S., and Uhlenbrook, S.: Trends in temperature and precipitation extremes in the Yellow River source region, China, Climatic Change, 110, 403-429, doi:10.1007/s10584-011-0056$2,2012$.

Hu, Y., Maskey, S., and Uhlenbrook, S.: Downscaling daily precipitation over the Yellow River source region in China: a comparison of three statistical downscaling methods, Theor. Appl. Climatol., 112, 447-460, doi:10.1007/s00704-012-0745-4, 2013. 
Hundecha, Y. and Bárdossy, A.: Statistical downscaling of extremes of daily precipitation and temperature and construction of their future scenarios, Int. J. Climatol., 28, 589-610, doi:10.1002/joc.1563, 2008.

Immerzeel, W. W., van Beek, L. P. H., and Bierkens, M. F. P.: Climate change will affect the Asian water towers, Science, 328, 1382-1385, 2010.

IPCC - Intergovernmental Panel on Climate Change: Climate change 2007: the Physical Science Basis Summary for Policymakers Contribution of Working Group I to the Fourth Assessment Report of the Intergovernmental Panel on Climate Change, Cambridge University Press, Cambridge, 996 pp., 2007.

Kalnay, E., Kanamitsu, M., Kistler, R., Collins, W., Deaven, D., Gandin, L., Iredell, M., Saha, S., White, G., Woollen, J., Zhu, Y., Leetmaa, A., Reynolds, B., Chelliah, M., Ebisuzaki, W., Higgins, W., Janowiak, J., Mo, K. C., Ropelewski, C., Wang, J., Jenne, R., and Joseph, D.: The NCEP-NCAR 40-year reanalysis project, B. Am. Meteorol. Soc., 77, 437-471, 1996.

Kjellström, E., Bärring, L., Jacob, D., Jones, R., Lenderink, G., and Schär, C.: Modelling daily temperature extremes: recent climate and future changes over Europe, Climatic Change, 81, 249-265, doi:10.1007/s10584-006-9220-5, 2007.

Lan, Y., Zhao, G., Zhang, Y., Wen, J., Liu, J., and Hu, X.: Response of runoff in the source region of the Yellow River to climate warming, Quatern. Int., 226, 60-65, doi:10.1016/j.quaint.2010.03.006, 2010.

Liu, X. and Chen, B.: Climatic warming in the Tibetan Plateau during recent decades, Int. J. Climatol., 20, 1729-1742, 2000.

Liu, X., Yin, Z. Y., Shao, X., and Qin, N.: Temporal trends and variability of daily maximum and minimum, extreme temperature events, and growing season length over the eastern and central Tibetan Plateau during 1961-2003, J. Geophys. Res., 111, D19109, doi:10.1029/2005JD006915, 2006.

Liu, X., Cheng, Z., Yan, L., and Yin, Z.: Elevation dependency of recent and future minimum surface air temperature trends in the Tibetan Plateau and its surroundings, Global Planet. Change, 68, 164-174, 2009.

Lu, A., Kang, S., Li, Z., and Theakstone, W.: Altitude effects of climatic variation on Tibetan Plateau and its vicinities, J. Earth Sci., 21, 189-198, 2010.

Marengo, J. A., Rusticucci, M., Penalba, O., and Renom, M.: An intercomparison of observed and simulated extreme rainfall and temperature events during the last half of the twentieth century: part 2: historical trends, Climatic Change, 98, 509-529, 2010.

Maskey, S., Uhlenbrook, S., and Ojha, S.: An analysis of snow cover changes in the Himalayan region using MODIS snow products and in-situ temperature data, Climatic Change, 108, 391-400, doi:10.1007/s10584-011-0181-y, 2011.

Qin, J., Yang, K., Liang, S., and Guo, X.: The altitudinal dependence of recent rapid warming over the Tibetan Plateau, Climatic Change, 97, 321-327, 2009.

Ramanathan, V., Crutzen, P. J., Kiehl, J. T., and Rosenfeld, D.: Atmosphere - Aerosols, climate, and the hydrological cycle Science, 294, 2119-2124, doi:10.1126/science.1064034, 2001.

Rangwala, I., Miller, J., and Xu, M.: Warming in the Tibetan Plateau: possible influences of the changes in surface water vapor, Geophys. Res. Lett., 36, L06703, doi:10.1029/2009GL037245, 2009.
Rangwala, I. and Miller, J.: Climate change in mountains: a review of elevation-dependent warming and its possible causes, Climatic Change, 114, 527-547, doi:10.1007/s10584-012-0419-3, 2012.

Rangwala, I., Miller, J., Russell, G., and Xu, M.: Using a global climate model to evaluate the influences of water vapor, snow cover and atmospheric aerosol on warming in the Tibetan Plateau during the twenty-first century, Clim. Dynam., 34, 859-872, 2010.

Schoof, J. T., Shin, D. W., Cocke, S., LaRow, T. E., Lim, Y. K., and O'Brien, J. J.: Dynamically and statistically downscaled seasonal temperature and precipitation hindcast ensembles for the southeastern USA, Int. J. Climatol., 29, 243-257, doi:10.1002/joc.1717, 2009.

Shrestha, A. B. and Aryal, R.: Climate change in Nepal and its impact on Himalayan glaciers, Reg. Environ. Change, 11 (Suppl 1), S65-S77, doi:10.1007/s10113-010-0174-9, 2011.

Tebaldi, C., Hayhoe, K., Arblaster, J., and Meel, G.: Going to the extremes: an intercomparison of model-simulated historical and future changes in extreme events, Climatic Change, 79, 185-211, doi:10.1007/s10584-006-9051-4, 2006.

Viviroli, D., Archer, D. R., Buytaert, W., Fowler, H. J., Greenwood, G. B., Hamlet, A. F., Huang, Y., Koboltschnig, G., Litaor, M. I., López-Moreno, J. I., Lorentz, S., Schädler, B., Schreier, H., Schwaiger, K., Vuille, M., and Woods, R.: Climate change and mountain water resources: overview and recommendations for research, management and policy, Hydrol. Earth Syst. Sci., 15, 471-504, doi:10.5194/hess-15-471-2011, 2011.

Wang, X., Yang, T., Shao, Q., Acharya, K., Wang, W., and Yu, Z.: Statistical downscaling of extremes of precipitation and temperature and construction of their future scenarios in an elevated and cold zone, Stoch. Environ. Res. Risk A., 26, 405-418, doi:10.1007/s00477-011-0535-z, 2012.

Wang, X., Zhou, W., Wang, D., and Wang, C.: The impact of the summer Asian Jet Stream biases on surface air temperature in mid-eastern China in IPCC AR4 models, Int. J. Climatol., 33, 265-276, doi:10.1002/joc.3419, 2013.

Wetterhall, F., Bárdossy, A., Chen, D., Halldin, S., and Xu, C.: Daily precipitation downscaling techniques in three Chinese regions, Water Resour. Res., 42, W11423, doi:10.1029/2005WR004573, 2006.

Wetterhall, F., Halldin, S., and Xu, C. Y.: Seasonality properties of four statistical downscaling methods in central Sweden, Theor. Appl. Climatol., 87, 123-137, doi:10.1007/s00704-005-0223-3, 2007.

Wilby, R. L. and Dawson, C. W.: The statistical DownScaling Model: insights from one decade of application, Int. J. Climatol., 33, 1707-1719, doi:10.1002/joc.3544, 2013.

Wilby, R. L. and Wigley, T. M. L.: Precipitation predictors for downscaling: observed and general circulation model relationships, Int. J. Climatol., 20, 641-661, 2000.

Wilby, R. L., Dawson, C. W., and Barrow, E. W.: SDSM - a decision support tool for the assessment of regional climate change impacts, Environ. Model. Softw., 17, 145-157, 2002.

Wilby, R. L., Tomlinson, O. J., and Dawson, C. W.: Multi-site simulation of precipitation by conditional resampling, Clim. Res., 23, 183-194, 2003.

$\mathrm{Xu}, \mathrm{Z}$., Zhao, F., and Li, J.: Response of streamflow to climate change in the headwater catchment of the Yellow River basin, Quatern. Int., 208, 62-75, 2009. 
Yang, J.-S., Chung, E.-S., Kim, S.-U., and Kim, T.-W.: Prioritization of water management under climate change and urbanization using multi-criteria decision making methods, Hydrol. Earth Syst. Sci., 16, 801-814, doi:10.5194/hess-16-801-2012, 2012.

Yang, T., Hao, X., Shao, Q., Xu, C., Zhao, C., Chen, X., and Wang, W.: Multi-model ensemble projections in temperature and precipitation extremes of the Tibetan Plateau in the 21st century, Global Planet. Change, 80-81, 1-13, doi:10.1016/j.gloplacha.2011.08.006, 2012.

You, Q., Kang, S., Pepin, N., and Yan, Y.: Relationship between trends in temperature extremes and elevation in the eastern and central Tibetan Plateau, 1961-2005, Geophys. Res. Lett., 35, L04704, doi:10.1029/2007GL032669, 2008.
Zhang, Q., Xu, C., Zhang, Z., Ren, G., and Chen, Y.: Climate change or variability? The case of Yellow river as indicated by extreme maximum and minimum air temperature during 19602004, Theor. Appl. Climatol., 93, 35-43, doi:10.1007/s00704007-0328-y, 2008.

Zhou, T. J. and Yu, R. C.: Twentieth-century surface air temperature over China and the globe simulated by coupled climate models, J. Climate, 19, 5843-5858, doi:10.1175/JCLI3952.1, 2006. 